\title{
The IZA evaluation dataset survey: a scientific use file
}

\author{
Patrick Arni ${ }^{1}$, Marco Caliendo ${ }^{2}$, Steffen Künn ${ }^{3^{*}}$ and Klaus F Zimmermann ${ }^{3}$
}

\author{
* Correspondence: \\ kuenn@iza.org \\ ${ }^{3}$ Institute for the Study of Labor \\ (IZA), University of Bonn, \\ Schaumburg-Lippe-Str. 5-9, 53113 \\ Bonn, Germany \\ Full list of author information is \\ available at the end of the article
}

\begin{abstract}
This reference paper describes the sampling and contents of the IZA Evaluation Dataset Survey and outlines its vast potential for research in labor economics. The data have been part of a unique IZA project to connect administrative data from the German Federal Employment Agency with innovative survey data to study the out-mobility of individuals to work. This study makes the survey available to the research community as a Scientific Use File by explaining the development, structure, and access to the data. Furthermore, it also summarizes previous findings with the survey data.

JEL codes: $\mathrm{C} 81 ; \mathrm{H} 43 ; \mathrm{J} 68$

Keywords: Survey data; Scientific use file; Labor market policies; Evaluation; Migration; Ethnicity; Attitudes; Behavior; Skills
\end{abstract}

\section{Introduction}

In modern welfare states, active labor market policies (ALMP) such as job search assistance, training programs, public employment programs and wage subsidies are intended to reintegrate the unemployed back into the labor market. Given that countries spend significant shares of their budgets on activation measures (see OECD 2013), it is important for policy makers to ascertain if such programs indeed improve the labor market prospects of participants. In order to obtain reliable estimates for the impact of ALMP and understand why and how programs work or not, both appropriate econometric methods and suitable data are required. While the development of econometric methods and computational power has increased dramatically during recent decades, data availability or the information content of existing datasets still represent a bottleneck.

To overcome the problem of data limitations within the field of labor economics, IZA has recently implemented a large-scale survey, the IZA Evaluation Dataset Survey (IZA ED Survey). In contrast to population-representative surveys, this survey has the advantage that it captures a large entry sample of unemployed individuals and therefore includes large shares of participants in ALMP programs. In fact, the IZA ED Survey covers a panel of 17,396 individuals who registered as unemployed at the Federal Employment Agency in Germany between June 2007 and May 2008 ${ }^{1}$. Based on computer assisted telephone interviews (CATI), the individuals were interviewed up to four times. Starting at their entry into unemployment, the individuals were interviewed at

(C) 2014 Arni et al.; licensee Springer. This is an Open Access article distributed under the terms of the Creative Commons Attribution License (http://creativecommons.org/licenses/by/2.0), which permits unrestricted use, distribution, and reproduction in any medium, provided the original work is properly credited. 
frequent intervals during the first 12 months of unemployment and in the long-run after three years.

This data allows the researcher to observe dynamics with respect to individual and labor market characteristics during the early stage of unemployment, as well as tracking long-run outcomes. Within the survey, information on labor market activities, ALMP participation, migration background, search behavior, ethnic and social networks, psychological factors, cognitive and non-cognitive abilities, attitudes and preferences was recorded. Its large sample size of individuals entering unemployment, in combination with its broad set of variables and the measurement of unemployment dynamics (due to several interviews during the first three years after unemployment entry), offers new perspectives for empirical labor market research. Besides the evaluation of ALMP programs, this dataset provides a good empirical base to investigate all aspects of the transition process from unemployment to employment. In particular, the combination of rich information on individual characteristics and longitudinal data allows designing detailed studies concerning the interplay of personal (search) behavior and attitudes, labor market outcomes and labor market policies.

The IZA ED Survey is now available as a Scientific Use File. This paper introduces the concept of the Scientific Use File to the scientific community by illustrating the background and motivation for the creation of this dataset in Section 2, before explaining the development, structure and access to the data in Section 3. In Section 4, we provide an overview of applied studies that have used this dataset in the past, and provide some ideas on further possible fields of application and an outlook in Section 5.

\section{Background}

The starting point for the creation of the IZA ED Survey is based on the aforementioned existence of data limitations in the field of program evaluation. As a first step to overcome such limitations and obtain empirical evidence on the effectiveness of labor market policies, many European countries have recently opened their administrative databases for scientific research. The advantages of administrative data are straightforward: they are consistently and accurately collected, resulting in highly reliable data covering a large number of observations (in some cases even 100\% of the population). They are regularly updated such that long time periods are observable usually and the specific use of ALMP programs is directly visible. In addition, the provision of administrative data for scientific research reflects a cost-effective way of providing highly reliable and representative data, as these data are collected for administrative purposes anyway.

However, there are also some limitations associated with administrative data, reducing its usefulness for scientific purposes. Besides a very restrictive access due to data security issues, given that administrative data are collected for administrative purposes the range and variety of variables is quite restricted. Important variables for scientific research such as social networks, personality traits, cognitive skills, attitudes or ethnic identity are usually not important for administrators and hence are not included in administrative databases.

However, recent studies have shown the high relevance of such variables in empirical studies in the field of labor economics (e.g. Borghans et al. 2008, Bonin et al. 2007, 
Constant and Zimmermann 2008 and 2013). Further information that is also needed for labor market research yet not included in administrative data includes, for instance, information on job search behavior, such as reservation wages, search intensity or search channels, or job satisfaction and individuals' expectations concerning their future labor market success and health condition. Indeed, such information is crucial towards understanding why certain ALMP programs work and others do not. Thus, survey data are needed to answer fundamental research questions that cannot be answered by using administrative data.

In order to provide a base for empirical research on such questions of social behavior, many countries have started initiatives to create survey data for scientific purposes. The most known surveys are generally the large population-representative surveys such as the German Socio-Economic Panel (GSOEP), the Current Population Survey (CPS) in the U.S., the British Household Panel Survey (BHPS) or the recently started Household, Income and Labour Dynamics in Australia Survey (HILDA). Such surveys are widely used and depict the main workhorse in empirical social sciences.

However, they cannot solve the data restrictions within specific research areas such as the evaluation of ALMP programs, the economics of migration or education. In these areas, population representative surveys are not particularly appropriate as they capture insufficient information and sample sizes concerning certain subgroups of the population (e.g. job seekers, immigrants, pupils) or with respect to specific subjects (e.g. unemployment, migration aspects, school performance).

To overcome such data limitations, several institutions have started data initiatives to abolish particular data restrictions within certain research areas. For instance, the New Immigrant Survey in the US has been implemented to create a data base for analyzing policy questions on immigrants in the U.S. (see Jasso et al. 2000). Consistently, the Rural-to-Urban Migration Dataset was created to analyze the massive migration flows from rural to urban areas in China (see Kong 2010; Akgüc et al. 2013). Moreover, topic-specific surveys have also been implemented, e.g. the German Panel Analysis of Intimate Relationships and Family Dynamics (see Huinink 2011) to investigate mechanisms of intergenerational transmission or the German National Educational Panel Study (NEPS, see Blossfeld et al. 2011) to analyze questions within the field of economics of education.

In line with this strand of data projects, IZA has recently implemented the IZA ED Survey on unemployed individuals. The main aim of this survey is to generate an optimal data base for the evaluation of social and labor policies, as well as studying the transition process from unemployment back to employment. Therefore, the underlying population of the survey focuses solely on entries into unemployment, given that such individuals are primarily targeted by labor market policies. The survey is now available as a Scientific Use File, which will be distributed by the International Data Service Center (IDSC) of IZA ${ }^{2}$.

A distinctive and attractive feature of the IZA ED Survey is that it can be merged to administrative data as provided by the Institute for Employment Research (IAB) in Nuremberg, the research institute of the Federal Employment Agency (see Caliendo et al. 2011a for details). The administrative data cover daily information on individuals' labor market activities, including wages and benefits, for a period covering from 1975 until present. The merging of the IZA ED Survey with the administrative data provides 
the additional advantage of combining the variety of survey information with the high reliability and large observation window of the administrative data. However, the administrative data are subject to very restrictive data security legislation that currently prevents public access to the merged dataset. IZA is actively engaging in joint work with the IAB to find a solution that will provide access to the merged dataset in the future.

\section{The data}

The aim of the IZA ED Survey was to interview new entries into unemployment, collecting detailed information on these individuals and their labor market activities, starting at entry into unemployment until three years after. The following section describes the underlying target population, the construction of the survey, the questionnaire and characteristics of the finally realized samples, as well as providing guidance on data access. Thereby, the focus is solely on the main features of the data. A very detailed and more technical description of the data construction, including a description of the questionnaire, an extensive analysis of non-response and panel attrition, and the calculation of panel weights can be found in the User Manual of the IZA ED Survey ${ }^{3}$.

\subsection{The target population and sampling}

The IZA ED Survey consists of individuals who registered as unemployed at the German Federal Employment Agency within the period from June 2007 to May 20084. The aim was to construct a sample of "new" entries into unemployment, i.e. prime-age individuals who enter unemployment, are looking for a job and are eligible to participate in ALMP programs.

The contact information on individuals entering unemployment was drawn from the monthly unemployment inflow statistic of the Federal Employment Agency. This statistic records individuals when they register as unemployed at the Federal Employment Agency-if eligible to unemployment benefit type I-or the agency responsible for the unemployment benefit type II. While unemployment benefit type I is paid to individuals who made contributions to the unemployment insurance in the past, unemployment benefit type II is a means-tested, tax-funded benefit that is paid to long-term unemployed or individuals without any previous employment experience (see Konle-Seidl et al. 2010 for an overview on the German unemployment insurance system). Therefore, the unemployment inflow statistic contains a very heterogeneous pool of entries into unemployment, so that-based on the available information included in the unemployment inflow statistic-some restrictions were implemented in order to pre-select the target population (see Table 1 for an overview).

First of all, an age restriction was applied (16-54 years at entry into unemployment) to avoid any influence due to retirement decisions, e.g. individuals might voluntarily enter unemployment in order to retire earlier and bridge the time until the official retirement age. However, given that these individuals are not looking for a job they do not belong to our target population. Moreover, we excluded individuals who received unemployment benefit type II (subject to Social Code II, SGB II) at entry into unemployment, due to three reasons. First, unemployed individuals whose unemployment benefit type I entitlement elapses after being unemployed for a certain period (in most cases after 12 months) will be technically registered in the unemployment inflow 
Table 1 Applied sample restrictions

\begin{tabular}{l} 
Pre-interview restrictions applied to the sample drawn from the unemployment inflow statistic \\
\hline 1. Age restriction: 16-54 years at entry into unemployment \\
2. Exclusion of unemployment benefit type II recipients \\
3. Exclusion of re-entries into unemployment after a period of sickness or participation in ALMP programs \\
Restrictions during the interview \\
\hline 4. Verification of unemployment entry and previous activities by respondents \\
5. Exclusion of "pseudo" unemployment entries: Individuals who signed a contract for a new job \\
already at entry into unemployment and hence do not search for employment
\end{tabular}

statistic as an entry into unemployment benefit type II. In economic terms, however, this does not represent a new entry into unemployment and thus such individuals should be excluded from the sample. Second, the SGB II records are likely to be incomplete and third, individuals receiving unemployment benefit type II are not eligible to every ALMP program. Therefore, excluding unemployment benefit type II recipients narrows the sample towards the specified target population. As a last step, individuals who are likely to be re-entries into unemployment were excluded. The unemployment inflow statistic technically defines every individual who registers as unemployed after a certain period of not being unemployed as an entry into unemployment. Therefore, periods of sickness or participation in ALMP programs interrupt unemployment spells, so that individuals who did not find a job during that time are counted (again) as entries into unemployment. However, given that these interruptions do not terminate unemployment in economic terms, these spells are not "new" entries into unemployment and thus have to be excluded. Therefore, all individuals who registered as unemployed after a period of sickness or ALMP participation or had an entry into unemployment in the previous month were excluded.

In addition to the pre-interview sample restrictions, a very detailed screening took place at the beginning of each interview in order to finally identify the target population. This verification procedure was required as the available information provided by the unemployment inflow statistic only allowed for a raw identification of the target population. First of all, each individual had to answer several questions about his/her current unemployment entry to ensure that the individual unambiguously belongs to the pre-defined target population. Most importantly, as this is not observed in the unemployment inflow statistic, individuals who reported having already signed a contract for a new job at entry into unemployment were dropped, as they are not searching for employment.

This two-step procedure combining the pre-interview sample restrictions and the screening during the interview guarantees that only individuals who unambiguously belong to the specified target population were interviewed.

\subsection{Construction of the survey and response rates}

The IZA ED Survey is constructed as a panel where individuals entering unemployment within the period from June 2007 until May 2008 were interviewed at least three times, i.e. at entry into unemployment, as well as 12 and 36 months later (see Figure 1). In addition, three selected monthly cohorts, i.e. entries into unemployment in June and 


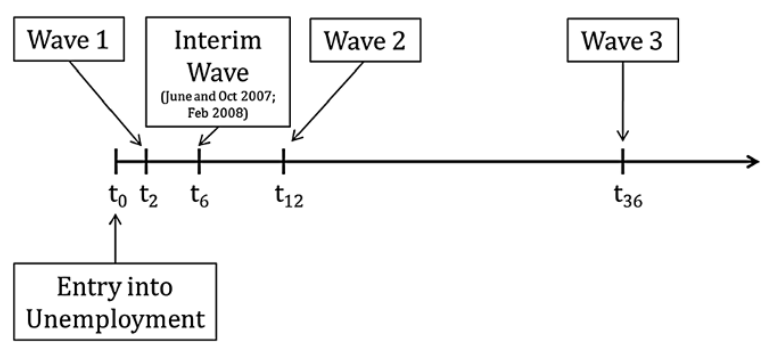

Figure 1 Structure of the survey.

October 2007, and February 2008, received an additional interview six months after entry into unemployment. The main aim of this interim wave is to measure dynamics with respect to changes in individual and labor market characteristics during the early stage of unemployment. Due to restricted financial means and the risk of higher panel attrition for these individuals, the interim wave was restricted to three cohorts only, distributed over the entire year to avoid any bias due to seasonality.

The interviews were performed by means of pre-tested computer assisted telephone interviews (CATI), conducted by a professional survey institute ${ }^{5}$. In advance of the interview, each individual received a letter prior to being contacted. The main aim of the letter was to increase the acceptance of the study and therefore participation rates by informing individuals about the content and background of the survey, as well as data security legislation. The interviews were held in German and, for the two most important immigrant groups in Germany-Russians and Turks-in their native language, if German language skills were insufficient.

As explained above, the contact information for potential interview respondents was provided by the unemployment inflow statistic of the German Federal Employment Agency, which records individuals entering unemployment on a monthly basis. Within the period of interest (May 2007 to June 2008), the inflow statistic recorded around eight million entries into unemployment. In order to interview each individual as immediately as possible after entry into unemployment, the survey was implemented on a monthly basis. At the end of each month, a random sample of new entries into unemployment was drawn from the unemployment inflow statistic (following the sample restrictions as depicted in Table 1) and immediately delivered to the survey institute.

Subsequently, the survey institute prepared the data for the interview and contacted the individuals in order to conduct an interview. In total, 81,399 addresses were available for the first interview. The data generating procedure, i.e. sample preparation, transfer to the survey institute and contacting of individuals, was successfully implemented within an average of only two months, so that the respondents received the first interview closely after entry into unemployment (indicated by $t_{2}$ in Figure 1 ). In subsequent interview waves, only individuals who agreed during the first interview to participate in subsequent waves were contacted again. Individuals who dropped out once were not contacted again, i.e. only respondents in wave 2 were contacted for an interview in wave 3.

Table 2 provides an overview of the finally realized interviews in each wave and sample. The upper part shows the numbers for the full sample, while the lower part provides a separate overview for the restricted sample only (three selected monthly entry 
Table 2 Number of observations

\begin{tabular}{|c|c|c|c|c|c|}
\hline \multicolumn{6}{|l|}{ Full sample } \\
\hline & \multicolumn{2}{|r|}{ Wave 1} & \multirow{2}{*}{$\begin{array}{l}\text { Wave } 2 \\
\text { Realized }\end{array}$} & \multirow{2}{*}{$\begin{array}{l}\text { Wave } 3 \\
\text { Realized }\end{array}$} & \\
\hline & Realized & Willing to participate in the panel & & & \\
\hline Number of interviews & 17,396 & 15,802 & 8,915 & 5,786 & \\
\hline$\%$ & 100 & 90.8 & 51.2 & 33.3 & \\
\hline$\%$ & --- & 100 & 56.4 & 36.6 & \\
\hline \multicolumn{6}{|c|}{ Restricted sample: Three selected entry cohorts (June and October 2007, February 2008) } \\
\hline & \multicolumn{2}{|r|}{ Wave 1} & Interim wave & Wave 2 & Wave 3 \\
\hline & Realized & Willing to participate in the panel & Realized & Realized & Realized \\
\hline Number of interviews & 4,423 & 4,060 & 2,548 & 1,589 & 985 \\
\hline$\%$ & 100 & 91.8 & 57.6 & 35.9 & 22.3 \\
\hline$\%$ & --- & 100 & 62.8 & 39.1 & 24.3 \\
\hline
\end{tabular}

cohorts). The objective for the first interview wave was to realize around 1,500 interviews each month, totaling approximately 18,000 interviews. It can be seen in the upper part of Table 2 that this goal was almost accomplished with 17,396 interviews realized in the first interview wave, whereby $90.8 \%$ agreed to participate in the panel. Based on these 15,802 observations, 8,915 interviews could be finally conducted in the second and 5,786 in the third wave, which corresponds to $51.2 \%$ and $33.3 \%$ of the initial sample. For the restricted sample, i.e. the three selected entry cohorts who also had an interim interview six months after entry into unemployment, 4,423 interviewees were available in the first interview wave, 2,548 in the interim, and 1,589 and 985 in the second and third wave, respectively. Panel attrition here is slightly higher than in the full sample, which is most likely due to the additional interview.

\subsection{Non-response and panel attrition}

Collecting data by a telephone survey bears the risk that the implementation of the survey introduces a selection bias, as individuals are free to choose whether or not to participate. Such a selection bias might arise due to selective non-response behavior at the first interview and attrition in later interview waves. An initial non-response bias occurs if the first interview can only be realized for a selective subsample of the underlying population, which will introduce a selection bias if the non-response is correlated with individual characteristics. Panel attrition occurs if individuals are willing to give an interview in the initial wave but drop out and do not return in subsequent interview waves, e.g. due to subsequent refusal, death, relocation or associated problems for tracing individuals. Similar to non-response, panel attrition will introduce a selectivity bias in the sampling if drop-outs are systematically correlated with individual characteristics. If one can credibly assume that selectivity is mostly driven by characteristics that are observed, the potential selection bias can be rebalanced by a weighting scheme.

In order to reveal whether the implementation of the first interview finally led to a representative sample of the target population, it would be necessary to compare characteristics of individuals who participated in the first interview wave with those of the underlying target population. Another possibility is to compare individuals who were 
contacted but refused to give an interview with survey participants. Both comparisons would answer the question of whether the realized sample suffers a non-response bias.

However, in the case of the IZA ED Survey, the final identification of the target population took place during the interview. This was necessary as some important screening characteristics are not observable in the unemployment inflow statistic, and thus individuals had to be contacted in order to finally verify whether or not they belong to the target population. As a consequence, the sample extracted from the unemployment inflow statistic and the sample of interview refusals still contain individuals who are not part of the target population. This actually prevents us from running a representative non-response analysis for the first interview wave. For instance, if we detected differences between interview refusals and survey participants, we could not conclude that such differences are driven by selective non-response behavior given that the group of refusals still contains individuals who are actually not eligible for an interview.

This is a common problem with telephone surveys where the final identification of the target population takes place during the interview. What is usually undertaken in such cases is to provide as much information as possible concerning the data generation process. We therefore provide a descriptive comparison of survey participants with the sample extracted from the unemployment inflow statistic and interview refusals with respect to observable characteristics in Table 3.

It can be seen that the realized sample in wave 1 differs from the two other samples in terms of observable characteristics. We find that women, natives and individuals with higher school attainment have a higher probability of participating in the survey. Although the differences are small, they are mostly statistically significant (as indicated by respective p-values). However, as explained above, we do not know whether these

Table 3 Comparison of gross sample, refusals and realized sample in wave 1

\begin{tabular}{|c|c|c|c|c|c|}
\hline & \multirow{2}{*}{$\begin{array}{c}\text { Gross } \\
\text { Sample } \\
\text { (1) }\end{array}$} & \multicolumn{2}{|r|}{ Wave 1} & \multicolumn{2}{|c|}{ p-value } \\
\hline & & $\begin{array}{l}\text { Refusals } \\
\text { (2) }\end{array}$ & $\begin{array}{c}\text { Realized sample } \\
\text { (3) }\end{array}$ & (1) vs. (3) & (2) vs. (3) \\
\hline Number of observations & 81,391 & 5,388 & 17,396 & & \\
\hline Female & 43.9 & 44.5 & 47.4 & 0.000 & 0.000 \\
\hline \multicolumn{6}{|l|}{ Age category } \\
\hline$\leq 24$ years & 28.0 & 28.0 & 27.6 & 0.263 & 0.581 \\
\hline 25 to 34 years & 26.6 & 25.7 & 26.1 & 0.114 & 0.631 \\
\hline 35 to 44 years & 24.6 & 25.7 & 25.1 & 0.308 & 0.281 \\
\hline$\geq 45$ years & 20.7 & 20.5 & 21.3 & 0.061 & 0.217 \\
\hline German citizen & 91.1 & 92.6 & 92.7 & 0.000 & 0.001 \\
\hline \multicolumn{6}{|l|}{ School degree } \\
\hline None, unknown & 8.0 & 6.6 & 5.4 & 0.000 & 0.001 \\
\hline Lower secondary school & 34.7 & 35.2 & 30.5 & 0.000 & 0.000 \\
\hline Middle secondary school & 36.5 & 37.3 & 37.6 & 0.007 & 0.666 \\
\hline Advanced middle sec. school & 7.6 & 8.0 & 9.3 & 0.000 & 0.003 \\
\hline Upper secondary school (A-level) & 13.2 & 12.9 & 17.1 & 0.000 & 0.000 \\
\hline
\end{tabular}

Note: Numbers are percentages and based on administrative information included in the unemployment inflow statistic. Gross sample: Sample extracted from the unemployment inflow statistic (excluding eight individuals due to missing information in observable characteristics). Refusals: Individuals who have been contacted and refused to give an interview but were willing to provide at least some information about their current labor market activities (so-called soft-refusals). P-values are based on a simple t-test of equal means. 
differences arise due to selective non-response behavior or because the gross sample and the refusals still contain individuals who do not belong to the target population. Therefore, we decided to follow different experts in the field of survey design and refrain from providing weights to correct for these differences ${ }^{6}$.

Assuming that the realized sample in the first interview wave is a random sample of the underlying target population, in a second step we assess whether attrition in subsequent interview waves introduces a selection bias. Given that only a small subgroup of the initial sample remains in the survey until the third interview (around 33\%, see Table 2), it is likely that panel attrition is correlated with certain individual characteristics. Therefore, we compare individuals in the first wave to those who also participate in later waves. We find that women, natives, better educated and older individuals, as well as those with more employment experience and higher earnings in the past are more likely to remain in the survey. Intuitively, we also find that individuals who faced communication problems during the first interview are less likely to give an interview again. Therefore, the analysis of survey drop-outs confirms that panel attrition in the IZA ED Survey is systematically correlated with observable characteristics. Panel weights are provided with the data in order to correct for selective panel attrition (see user manual for details).

\subsection{The questionnaire}

Table 4 provides an overview of the general structure of the questionnaire and a list of variables included in each wave. It can be seen that the majority of questions are included in each wave, so that the information was updated at different points in time (see Figure 1). Note that the list of variables only depicts a crude summary of the rich content of the survey, with each category indicated in Table 4 represented by several questions in the questionnaire (see Section 3.6 for access to the questionnaires).

The questionnaire consists of cross-sectional and longitudinal questions. The information collected in the cross-section relates to the time of the interview, e.g. 12 months after entry into unemployment in the case of the second wave. Here, individual and job search characteristics are recorded at each interview, which allows the data users to analyze changes over time. As we can see in Table 4, the cross-sectional part records information on the process of entering unemployment, socio-demographics, migration and social background, personality, labor market networks, household and job search characteristics, participation in ALMP programs, the role of the employment agency for job search, life satisfaction and transfer payments.

While such information was collected for all individuals, some questions were only asked to individuals belonging to the three selected entry cohorts that also received the interim wave (entries into unemployment in June and October 2007, and February 2008) in order to measure dynamics in these characteristics during the early stage of unemployment. Here, information is collected concerning an individual's motives to contact the employment agency, his/her willingness to compromise in order to find a job, health, psychical and psychological conditions, drinking and smoking behavior, cognitive skills and additional questions on labor market networks, personality, daily activities and routines as well as personal appearance.

In addition to the cross-sectional questions, the longitudinal section collects monthly information on labor market activities. Therefore, the respondents were asked at each 
Table 4 Content of the survey

\begin{tabular}{|c|c|c|c|c|}
\hline Variables & Wave 1 & Interim wave & Wave 2 & Wave 3 \\
\hline \multicolumn{5}{|c|}{ Cross-sectional information } \\
\hline Information on the initial unemployment entry & $x$ & & & \\
\hline Individual characteristics (e.g. age, sex, region etc) & $x$ & $x$ & $x$ & $x$ \\
\hline Migration and social background & $x$ & $x$ & $x$ & $x$ \\
\hline Language skills & $x$ & & $x$ & $x$ \\
\hline Education & $x$ & & & \\
\hline Personality (Big-5, Locus of control) & $x$ & $x$ & $x$ & $x$ \\
\hline Intergenerational transmission & $x$ & $x$ & $x$ & $x$ \\
\hline Labor market networks & $x$ & $x$ & $x$ & $x$ \\
\hline Household composition & $x$ & $x$ & $x$ & $x$ \\
\hline Household income & $x$ & $x$ & $x$ & $x$ \\
\hline Debts & $x$ & & $x$ & $x$ \\
\hline Life satisfaction & $x$ & $x$ & $x$ & $x$ \\
\hline Job search and reservation wage & $x$ & $x$ & $x$ & $x$ \\
\hline Role of Employment Agency (job search) & $x$ & $x$ & $x$ & $x$ \\
\hline Details on placement/education voucher & $x$ & $x$ & $x$ & $x$ \\
\hline Benefit receipt and sanctions & $x$ & $x$ & $x$ & $x$ \\
\hline Labor market activity at interview & & $x$ & & \\
\hline Participation in ALMP & & $x$ & & \\
\hline Interview-specific information (e.g. date, language) & $x$ & $x$ & $x$ & $x$ \\
\hline Willingness to compromise during job search ${ }^{\text {a) }}$ & $x$ & $x$ & $x$ & $x$ \\
\hline Motivation to contact Employment Agency ${ }^{\text {a) }}$ & $x$ & & & \\
\hline Health and physical conditiona) & $x$ & $x$ & $x$ & $x$ \\
\hline Emotional and psychological conditions $\mathrm{s}^{\mathrm{a})}$ & $x$ & $x$ & & \\
\hline Drinking and smoking behavior ${ }^{a}$ & $x$ & $x$ & $x$ & $x$ \\
\hline Change of labor market networks during unemployment ${ }^{a)}$ & $x$ & $x$ & $x$ & $x$ \\
\hline Personality (risk, trust, patience, reciprocity)a) & $x$ & $x$ & $x$ & $x$ \\
\hline Cognitive tests ${ }^{\mathrm{a})}$ & $x$ & $x$ & $x$ & $x$ \\
\hline Daily activities and routines ${ }^{\mathrm{a})}$ & $x$ & $x$ & $x$ & $x$ \\
\hline Personal appearance ${ }^{a)}$ & $x$ & $x$ & $x$ & $x$ \\
\hline \multicolumn{5}{|c|}{ Longitudinal information on labor market activities } \\
\hline Dependent employment & $x$ & & $x$ & $x$ \\
\hline Self-employment & $x$ & & $x$ & $x$ \\
\hline Unemployment & $x$ & & $x$ & $x$ \\
\hline Participation in ALMP & $x$ & & $x$ & $x$ \\
\hline School attendance & $x$ & & $x$ & $x$ \\
\hline Professional training & $x$ & & $x$ & $x$ \\
\hline Internship & $x$ & & $x$ & $x$ \\
\hline Other activities & $x$ & & $x$ & $x$ \\
\hline
\end{tabular}

${ }^{a)}$ Filled for individuals belonging to the three selected monthly cohorts who also received the interim wave (entries in unemployment in June and October 2007, and February 2008).

interview (except the interim wave) to update their labor market biography retrospectively, starting at the last interview or, in the case of the first interview, at unemployment entry. Besides recording the labor market activity and its duration in terms of 
calendar months, very detailed associated information such as earnings, working time or search strategies were also recorded. Ultimately, the longitudinal part allows the data user to reconstruct the complete labor market biography (including spell-specific information) starting at entry into unemployment $\left(\mathrm{t}_{0}\right)$ and ending at the last interview in which the individual has participated.

The large amount of information collected by the survey is reflected by the average duration of the interviews, as shown in Table 5, with the first interview taking an average of 58 minutes $^{7}$. The average duration declined in subsequent interviews, which is mainly due to learning effects, i.e. individuals had to answer the same questions several times, as well as a reduction of questions included in subsequent waves (see Table 4). In particular, the exclusion of longitudinal questions about an individual's labor market activities significantly reduced the average duration in the interim wave.

\subsection{Descriptive statistics}

Table 6 describes the survey participants, based on information reported in the first interview. It can be seen that $47 \%$ of participants are female, $30 \%$ are located in East Germany, $40 \%$ are married and the clear majority (94\%) are German citizens, although $13 \%$ are born abroad. With respect to labor market activities prior to entry into unemployment, it can be seen that participants spent on average $63 \%$ of their lifetime during working age in employment. Among the individuals who were employed at least once in their working life the median net earnings from their last employment amounted to 1100 Euro/month. Only a minority of $16 \%$ had no employment experience at all before entering unemployment.

In addition, Table 7 shows the distribution of selected outcome variables at each interview. As the implementation of the survey introduced a selection bias due to non-random panel attrition, we provide both the observed and weighted values for subsequent interview waves, calculated using the panel weights that are provided with the data.

First of all, it can be seen that the majority of individuals are able to find employment within the observation window. $25.1 \%$ are employed two months after entry into unemployment (at wave 1), increasing to $73.4 \%$ after 36 months (at wave 3). Furthermore, it can be seen that the share in unemployment decreases over time, while the share in education is quite stable at around 7-9\% (after an initial adjustment).

More interestingly, Table 7 shows the share of individuals who are affected by different labor market policies over time, thus illustrating the high potential of the dataset to evaluate such policies. It can be seen that significant shares of individuals participate in active labor market policy programs, including vocational training, job creation schemes, wage and start-up subsidies, etc. While $10.3 \%$ participated in such a program between entry into unemployment and first interview, this increased to $27.9 \%$ between the first and second interview. In total, $26.3 \%$ of all individuals in the survey participated at least once within the observation window.

Table 5 Interview duration

\begin{tabular}{lcccc}
\hline & Wave $\mathbf{1}$ & Interim wave & Wave 2 & Wave 3 \\
\hline Number of observations & 17,396 & 2,548 & 8,915 & 5,786 \\
Average duration of interviews (in minutes) & 58 & 27 & 41 & 36 \\
\hline
\end{tabular}




\begin{tabular}{|c|c|}
\hline & Survey participants \\
\hline Number of observations & 17,396 \\
\hline Female & 47.4 \\
\hline Age (in years) & 33.8 \\
\hline East Germany & 29.5 \\
\hline Married & 39.8 \\
\hline German citizen & 94.2 \\
\hline Not born in Germany & 12.5 \\
\hline Upper secondary school (A-level) & 20.6 \\
\hline \multicolumn{2}{|l|}{ Labor market experience before entry into unemployment } \\
\hline Share of working lifetime spent in employment & 62.9 \\
\hline Last earnings from employment (in $€ /$ month, net), mean & 1173.9 \\
\hline $25^{\text {th }}$ centile & 770 \\
\hline median & 1100 \\
\hline $75^{\text {th }}$ centile & 1400 \\
\hline No employment experience & 16.0 \\
\hline
\end{tabular}

Note: Numbers are percentages (unless otherwise indicated) and based on the first interview wave.

The data allow a detailed view on ALMP participation by type of programs. Among the surveyed job seekers, 9.4\% participated at least once within the observation window in a short-term training. This type of programs consists of activities like application training, language courses etc. over a short period of time. The participation rate in retraining-longer-run programs of (re)education-amounts to $8.7 \%$, the one in public employment schemes to $1.6 \%$. The latter program type features publicly sponsored work activities which are not valued by the labor market ("One-Euro-Jobs") and job creation schemes. Wage subsidies and start-up subsidies (to launch self-employment) are assigned to $5 \%$ and $5.6 \%$ of the individuals, respectively. These participation rates are well comparable to the corresponding figures of the official labor market statistics for the years of 2007 and $2008^{8}$. Moreover, these rates and the related numbers of observations demonstrate that the IZA ED Survey allows specific treatment effect analyses for different types of ALMP programs separately.

In addition, Table 7 also shows separate numbers with respect to the receipt of education and placement vouchers. These innovative measures have been introduced in Germany in 2003 and are supposed to improve the allocation of training programs (education voucher) and outsource job search assistance to private placement agencies (placement voucher). While previous evaluation studies on education vouchers focused on the effects of voucher redemption (see Rinne, Uhlendorff, Zhao 2012) due to data restrictions, the IZA ED Survey provides information on both voucher receipt and redemption. This allows a deeper analysis of the education vouchers' effectiveness as an innovative allocation mechanism of ALMP (for example, potential intention-to-treat effects triggered by voucher receipt). Table 7 shows that $4.6 \%$ received such a voucher until the first interview, with this share increasing to $9.9 \%$ between wave 1 and wave 2 . In total, $8.4 \%$ received an education voucher within our sample and observation window.

The survey data also include very detailed information on the receipt of a placement voucher and the resulting job search success, which provides many research opportunities. 
Table 7 Distribution of selected outcome and treatment variables over time

\begin{tabular}{|c|c|c|c|c|c|}
\hline & Total & Wave 1 & Interim wave & Wave 2 & Wave 3 \\
\hline Number of observations & 17,396 & 17,396 & 2,548 & 8,915 & 5,786 \\
\hline \multicolumn{6}{|l|}{ Labor market status } \\
\hline \multirow[t]{2}{*}{ Employed (self- or dependent employed) } & - & 25.1 & 55.7 & 62.9 & 73.4 \\
\hline & - & & $(55.8)$ & $(60.1)$ & $(72.4)$ \\
\hline \multirow[t]{2}{*}{ Unemployed } & - & 66.6 & 29.6 & 23.4 & 12.9 \\
\hline & - & & $(29.1)$ & $(24.8)$ & $(13.2)$ \\
\hline \multirow[t]{2}{*}{ Education } & - & 3.3 & 9.1 & 7.3 & 7.1 \\
\hline & - & & $(9.3)$ & $(8.3)$ & $(7.8)$ \\
\hline \multirow[t]{2}{*}{ Others } & - & 5.0 & 5.6 & 6.3 & 6.6 \\
\hline & - & & $(5.7)$ & $(6.8)$ & $(6.7)$ \\
\hline \multicolumn{6}{|c|}{ Affected by labor market policies between interviews ${ }^{\mathrm{a})}$} \\
\hline \multirow[t]{2}{*}{ Participation in active labor market programs } & 26.3 & 10.3 & 33.2 & 27.9 & 14.7 \\
\hline & & & $(33.2)$ & $(26.1)$ & $(15.1)$ \\
\hline \multirow[t]{2}{*}{ Short-term training } & 9.4 & 4.6 & 16.7 & 5.5 & 2.4 \\
\hline & & & $(16.6)$ & $(5.5)$ & $(2.5)$ \\
\hline \multirow[t]{2}{*}{ Retraining } & 8.7 & 3.3 & 7.6 & 8.9 & 6.3 \\
\hline & & & $(7.4)$ & $(8.3)$ & $(6.5)$ \\
\hline \multirow[t]{2}{*}{ Public employment scheme } & 1.6 & 0.4 & 3.6 & 1.1 & 1.1 \\
\hline & & & $(4.0)$ & $(1.2)$ & $(1.2)$ \\
\hline \multirow[t]{2}{*}{ Wage subsidy ${ }^{\text {b) }}$} & 5.0 & - & 5.5 & 6.1 & 4.4 \\
\hline & & & $(5.7)$ & (5.6) & $(4.4)$ \\
\hline \multirow[t]{2}{*}{ Start-up subsidy } & 5.6 & 2.2 & 5.5 & 7.5 & 1.8 \\
\hline & & & $(5.0)$ & $(6.3)$ & $(1.7)$ \\
\hline \multirow[t]{2}{*}{ Received education voucher } & 8.4 & 4.6 & 7.2 & 9.9 & - \\
\hline & & & $(6.8)$ & $(9.3)$ & - \\
\hline \multirow[t]{2}{*}{ Received placement voucher } & 11.2 & 5.4 & 13.1 & 11.8 & - \\
\hline & & & $(13.0)$ & $(11.6)$ & - \\
\hline \multirow[t]{2}{*}{ Sanction in unemployment benefits } & 8.6 & 5.0 & 4.2 & 7.5 & 2.5 \\
\hline & & & $(4.5)$ & (8.6) & $(2.7)$ \\
\hline
\end{tabular}

Note: Table shows observed values as percentages; weighted values for panel attrition are in parentheses.

a) Share of individuals affected by different policies between current and previous interview (or entry into unemployment in case of wave 1). Numbers for wave 2 refer to the entire period between the first and second interview. Several policies can apply to an individual within the respective time span.

b) Information is not available for wave 1 .

Here, we observe that $11.2 \%$ of the respondents received a placement voucher within our observation window, with $5.4 \%$ already receiving a voucher very early during their unemployment spell (reported in wave 1). Later on, the numbers increase to $11.8 \%$, as reported in wave 2 .

Besides the participation in a particular program, another key policy that significantly influences the job search behavior of unemployed individuals-in the case that they do not comply with the instructions by the caseworker-is to reduce their unemployment benefits. The IZA ED Survey also includes detailed information on this issue, with Table 7 showing that $8.6 \%$ of the individuals were sanctioned at least once within the survey period. Besides the amount and exact timing (announcement, duration) of the sanction, the reason and its subjective assessment by the job seeker are also recorded. 
Thus, in sum, the comparative advantage of the IZA ED Survey data is particularly given by the fact that it combines rich information about an individual's behavior, attitudes and characteristics with precise and detailed information on ALMP and labor market activities and outcomes. This opens new perspectives for exploring the interactions of these variables.

\subsection{Data access}

The data are available as Scientific Use Files provided by the IDSC of IZA. In order to acquire more information about how to access to the Scientific Use Files, visit http:// idsc.iza.org/iza-ed-survey.

\section{Previous research using the IZA ED survey}

The richness of the dataset provides the basis for a broad set of potential research questions. This can be illustrated using the existing studies with the IZA ED Survey. Table 8 provides an overview of these contributions.

The first strand of studies focuses on the existence of ex ante effects of ALMP programs. Usually, evaluation studies investigate ex post effects on the labor market performance of actual participants. However, the pure announcement of participation in a program might already have an impact on the job search behavior of job seekers. Based on administrative data alone, it is difficult to determine the behavioral mechanics of how ex ante effects operate, given that information on an individual's job search is not included. In contrast, the IZA ED Survey includes information on both the subjective probability of participating in an ALMP program and very detailed information concerning the job search behavior of individuals, such as reservation wages and search channels.

Using this data, van den Berg et al. (2009) find results suggesting that a high perceived participation probability leads to lower reservation wages and increased search effort. It seems that job seekers try to avoid program participation. The pure announcement of program participation has a "positive" effect on the current job search behavior.

Given that the IZA ED Survey also contains detailed information on migration background, van den Berg et al. (2011) go one step further and run this analysis for different groups of migrants. They find that the ex ante effects differ considerably across migrant groups, most likely due to cultural differences across these groups.

The second strand of studies using the IZA ED Survey concerns the analysis of job search behavior of unemployed job seekers. Besides the evaluation of ALMP programs, this dataset also provides a good empirical base to investigate the job search behavior of job seekers due to the inclusion of several questions about the job search activities of unemployed individuals, such as reservation wages, search channels, willingness to take difficulties to find employment, regional mobility, role of employment agency, etc. The variety of variables included in the IZA ED Survey facilitates studies delivering essential new insights in the field of economics of information and job search.

For instance, Caliendo et al. (2011b) investigate the role of social networks on job search behavior, finding that individuals with larger social networks more commonly use informal search channels and also tend to have higher reservation wages. Moreover, Caliendo and Uhlendorff (2011) discuss how personality traits and (similar to the 
Table 8 Overview of previous studies using the IZA ED survey

\section{Nr. Study} Field/Research question

1 van den Berg et al. (2009) Ex ante effects of ALMP participation

2 van den Berg et al. (2011) Ex ante effects of ALMP participation: Effect heterogeneity with respect to country of origin of migrants

3 Caliendo et al. (2011b) Role of social networks for job search choices of unemployed job seekers

4 Caliendo, Uhlendorff (2011) Impact of personality and subjective expectations on job search behavior of unemployed individuals

5 Caliendo, Lee (2013)

$6 \quad$ Krause (2013)

7 Constant et al. (2011a)

8 Constant et al. (2010) Analysis of reservation wages of first and second generation migrants Impact of obesity on job search behavior and job finding probabilities Impact of happiness on job search, job finding probabilities and re-entry wages

Investigates to what extent the native-migrant gap in economic outcomes can be explained by differences in ethnic identity of migrants and its impact on job search behavior and transition to employment

9 Constant et al. (2011 b) Comparison of second generation migrants and natives with respect to the economic impact of attitudes and risk preferences

\section{Major finding}

Prospect of participating in ALMP programs reduces ex ante

reservation wages and increases search effort

Effects differ considerably by migrant group, probably due to cultural differences

Individuals with larger networks shift towards more intense use of

informal networks and have higher reservation wages

Heterogeneous impacts on job search behavior and transition probabilities to employment

Significant impact only for obese women: Lower employment probability and lower wages

Inverse u-shaped relationship between happiness of job seekers and re-employment probability and wages. Happier job seekers exert less search effort.

Less integrated migrants slowly reintegrate into employment, most likely attributable to lower search effort and relatively high reservation wages within this group.

Second generation migrants have higher reservation wages than first generation migrants as they tend to refer to the wage level within the host county, instead of the country of origin

Differences in attitudes and risk preferences explain lower employment probabilities among second generation migrants 
studies on ex ante effects of ALMP programs) the perceived probability to participate in an ALMP program affect job search behavior and consequently the transition to employment.

Caliendo and Lee (2013) use information on the weight of job seekers to test the hypothesis that overweight individuals behave or are treated differently during job search compared to normal weight individuals. Interestingly, they only find negative labor market effects for overweight women, i.e. lower employment probabilities and lower wages compared to normal weight women. For men, obesity apparently does not alter job search behavior and harm job finding probabilities.

Krause (2013) investigates the influence of individuals' happiness on reemployment probabilities and reentry wage levels of unemployed job seekers. By accounting for the individual's labor market history and information about future job prospects, it was possible to reduce reverse causality bias. The author finds an inverse $\mathrm{u}$-shaped relationship, which means that the optimal level of happiness is not necessarily the highest to maximize reemployment probabilities and wages. The effect on reemployment is driven by the concept of locus of control and the personality traits of neuroticism and extraversion. Interestingly, job search behavior, as measured by the number of search channels and applications sent out, is negatively correlated with an individual's happiness, in the sense that happier job seekers exert less job search effort.

The third strand of studies using the IZA ED Survey addresses different questions within the literature concerning the economics of migration. Besides information on job search behavior, the dataset includes detailed information on the migration and social background of individuals and their parents, language skills, religious affiliation and ethnic identity. Using this information, Constant et al. (2011a) investigate the extent to which the native-migrant gap in the labor market (migrants face lower employment probabilities and earnings) can be explained by ethnic identity and social integration. Applying a recently developed concept to differentiate between groups of migrants in terms of ethnic identity, the so-called ethnosizer (developed by Constant et al. 2009), the authors find that ethnic identity plays an important role in explaining differences in employment outcomes between natives and migrants. The lower employment rates among less integrated migrants can be attributed to lower search effort and relatively high reservation wages.

Constant et al. (2010) address the question of why the native-migrant distance in terms of economic outcomes persists over migrant generations despite second generation migrants achieving higher educational outcomes than their parents. In fact, they test the hypothesis of whether second generation migrants (born in Germany) have higher reservation wages than first generation migrants (not born in Germany), given that the former tend to orientate towards the wage level in the host country while the latter refer to their country of origin (where wages are on average lower than in Germany). Indeed, they find higher reservation wages for second generation migrants, which might explain the persistence of the nativemigrant gap in economic outcomes, although second generation migrant catch up in terms of educational attainment.

Constant et al. (2011b) extend the analysis of second generation migrants and compare them to natives in order to understand the persistence of the native-migrant gap. They find considerable differences in terms of attitudes and risk preferences, which 
however, do not explain lower employment probabilities among second generation migrants.

These existing studies illustrate the high potential of the IZA ED Survey for empirical research. They demonstrate as well that the range of potential research questions which can be addressed by the data is broad. However, the fact that the data have been collected by means of surveys and the focus on (initially) unemployed individuals provide natural restrictions to applications. Thus, the addressable research questions need to be focused on issues related to individual employment histories which start with registered unemployment. Research questions dealing, for example, with on-the-job search are not in the scope of the data. Two further restrictions which need to be taken into account are the non-negligible attrition (see Section 3.3), in case researchers want to address dynamic questions, and potential measurement noise in survey responses on behavioral questions like reservation wages or personality traits etc.

Overall, however, it can be stated that the variety of information included in this survey allows researchers to contribute new insights to many different issues within the field of labor economics.

\section{Summary and outlook}

This paper introduces the IZA ED Survey, which has been created to overcome data limitations in empirical labor research, particularly to provide more evidence about how successful job search and ALMP interventions operate. Beyond this aim, this panel survey can be used to study many issues within labor economics that set high demands on data richness. The new Scientific Use Files provided by the International Data Service Center of IZA cover a large and representative population of around 18,000 unemployed individuals who entered unemployment insurance in Germany between May 2007 and June 2008. The individuals were repeatedly interviewed over four waves in order that their labor market trajectories can be observed up to three years after unemployment entry. This large sample of unemployed individuals allows for more detailed and heterogeneity analyses (of subgroups, etc.) than a usual general-interest panel survey.

The core advantage of the IZA ED Survey is reflected in the combination of several types of crucial information within one data set: It provides very rich information on job search behavior, personal attitudes, traits, perceptions and characteristics as well as concerning the social and cultural environment of the surveyed individuals, including ethnicity and a migration background. This is combined with longitudinal data that track the individual pathways with respect to labor market activities and outcomes, as well as ALMP participations. Therefore, this data collection allows designing detailed studies regarding the interplay of personal (search) behavior and attitudes, labor market outcomes and labor market policies.

Accordingly, the goal of the provision of the IZA ED Survey to the scientific community is to inspire more research about the mentioned interplay. Some potential future lines of research based on the IZA ED Survey could include the analysis of dynamics of some of the aforementioned aspects, as well as their impact on labor market outcomes. Evaluations of labor market policies can be enriched by the study of these aspects, in order to provide more empirical evidence on how ALMP needs to be designed in order to be successful. Moreover, potential research questions can go far beyond these topics. 
For instance, getting to know more about the search behavior of different subgroups of the population (different ages, different cultural backgrounds, etc.) can be instructive for future policy design. More generally, the IZA ED Survey provides a collection of data which allow for potentially innovative empirical research that combines issues of different economic subfields, like e.g. behavioral economics, unemployment insurance and welfare system design, education, migration and public economics.

Finally, the construction of the IZA ED Survey was part of a broader project aimed at creating a new data base to analyze social and labor policies (see Caliendo et al. 2011a for details). Thereby, the main feature is that the survey data, as presented here, can be merged with individuals' administrative data as provided by the IAB. The administrative data contain daily information on individuals' time spent in employment, unemployment and participation in ALMP programs, including wages and benefits. Merging the survey with administrative data has the advantage that the variety of information included in the survey is enriched by highly reliable information on individuals' labor market activities and earnings, which are observable for a period that is much longer than the survey window (covering from 1975 until present). However, the administrative data are subject to German data security legislation, which prevents public access to the merged dataset. Therefore, we cannot yet provide the administrative information with the Scientific Use Files of the IZA ED Survey, although we are currently workingtogether with the IAB-on a solution to provide user access to the merged dataset in the future.

\section{Endnotes}

${ }^{1}$ The German Federal Employment Agency reports an annual unemployment rate of $9.0 \%$ and $7.8 \%$ in 2007 and 2008, respectively.

${ }^{2}$ The IDSC is another initiative by IZA to improve data availability within labor economics. The IDSC is embedded into a larger recent initiative by the German Council for Social and Economic Data to create an infrastructure for data access and documentation in Germany (see Solga and Wagner 2007). The idea is to establish a network of Research Data Centers and Data Service Centers in order to improve data access and transparency for the scientific community.

${ }^{3}$ The User Manual of the IZA ED Survey can be found at http://idsc.iza.org/iza-edsurvey.

${ }^{4}$ The time period was arbitrarily chosen but captures one complete year, so that seasonality in the labor market can be taken into account in empirical analyses.

${ }^{5}$ The survey was conducted by infas, the Institute for Applied Social Sciences, which is a private and independent market and social research institution in Bonn, Germany.

${ }^{6}$ We thank Martin Spiess (University Hamburg), Doris Hess and Reiner Gilberg (infas) for their advice on the non-response analysis.

${ }^{7}$ Despite the long interview duration, only $2-3 \%$ of the interview refusals reported that they refused to participate in the survey due to the interview duration (see user manual for a detailed analysis of interview refusals).

${ }^{8}$ The official labor market statistics ("Arbeitsmarktberichte" of the German Federal Employment Agency) reports about 4.2 million unemployment entries (into SGB III) 
per year, on average for 2007 and 2008. Among those, bit more than 0.5 million entries into short-term training are registered, which corresponds to a participation rate of 13.2\%. The figures for retraining are 5.6\%, for public employment Schemes $0.3 \%$, for wage subsidies $3.3 \%$ and for start-up subsidies $2.9 \%$. Note that these are stock figures, i. e. several participations per year and type of program can be registered. As a consequence, rates on short-term activities are higher in these statistics than in Table 7, and vice versa for longer-run activities.

\section{Competing interests}

The IZA Journal of European Labor Studies is committed to the IZA Guiding Principles of Research Integrity. The authors declare that they have observed these principles.

\section{Acknowledgements}

The IZA Evaluation Dataset Survey was created with financial support of the Deutsche Post Foundation. Furthermore, financial support by the German Science Foundation within the research project SPP 1169 "Flexibility in Heterogeneous Labour Markets" and the assistance of the Institute for Employment Research (IAB) in Nuremberg in data construction are kindly acknowledged.

Responsible editor: Martin Kahanec

\section{Author details}

'DEEP (Lausanne) and CAFÉ (Aarhus), Institute for the Study of Labor (IZA), Schaumburg-Lippe-Str. 5-9, 53113 Bonn, Germany. ${ }^{2}$ IZA, DIW Berlin and IAB, University of Potsdam, August-Bebel-Str. 89, 14482 Potsdam, Germany. ${ }^{3}$ Institute for the Study of Labor (IZA), University of Bonn, Schaumburg-Lippe-Str. 5-9, 53113 Bonn, Germany.

Received: 6 November 2013 Accepted: 19 February 2014

Published: 21 Mar 2014

\section{References}

Akgüc M, Giulietti C, Zimmermann KF (2013) The RUMiC Longitudinal Survey: Fostering Research on Labor Markets in China. Working Paper, IZA Bonn

Van den Berg G, Bergemann A, Caliendo M (2009) The effect of active labor market programs on not-yet treated unemployed individuals. J Eur Econ Assoc 7(2-3):606-616

Van den Berg G, Bergemann A, Caliendo M, Zimmermann KF (2011) The threat effect of participation in active labor market programs on job search behavior of migrants in Germany. Int J Manpow 32(7):777-795

Blossfeld HP, Roßbach HG, Von Maurice J (ed) (2011) Education as a Lifelong Process: The German National Educational Panel Study (NEPS). VS Verlag für Sozialwissenschaften, Wiesbaden

Bonin H, Dohmen T, Falk A, Huffman D, Sunde U (2007) Cross-sectional earnings risk and occupational sorting: the rolfe of risk attitudes. Labour Econ 14(6):926-937

Borghans L, Duckworth AL, Heckman JJ, Ter Weel B (2008) The economics and psychology of personality traits. J Hum Resour 43(4):972-1059

Caliendo M, Falk A, Kaiser LC, Schneider H, Uhlendorff A, van den Berg GJ, Zimmermann KF (2011a) The IZA evaluation dataset: towards evidence-based labor policy making. Int J Manpow 32(7):731-752

Caliendo M, Lee WS (2013) Fat chance! Obesity and the transition from unemployment to employment. Econ Hum Biol 11(2):121-133

Caliendo M, Schmidl R, Uhlendorff A (2011b) Social networks, job search methods and reservation wages: evidence for Germany. Int J Manpow 32(7):796-824

Caliendo M, Uhlendorff A (2011) Determinanten des Suchverhaltens von Arbeitslosen: Ausgewählte Erkenntnisse basierend auf dem IZA Evaluationsdatensatz. J Labour Market Res 44(1-2):119-125

Constant AF, Gataullina L, Zimmermann KF (2009) Ethnosizing immigrants. J Econ Behav Organ 69(3):274-287

Constant AF, Kahanec M, Rinne U, Zimmermann KF (2011a) Ethnicity, job search and labor market reintegration of the unemployed. Int J Manpow 32(7):753-776

Constant AF, Krause A, Rinne U, Zimmermann KF (2011b) Economic preferences and attitudes of the unemployed: are natives and second generation migrants alike? Int J Manpow 32(7):825-851

Constant AF, Krause A, Rinne U, Zimmermann KF (2010) Reservation Wages of First and Second Generation Migrants. IZA Discussion Paper 5396, Bonn

Constant AF, Zimmermann KF (2013) Migration, Ethnicity and Economic Integration. In: Constant A, Zimmermann KF (ed) International Handbook on the Economics of Migration. Edward Elgar Publishing, Cheltenham, pp 13-36. published

Constant AF, Zimmermann KF (2008) Measuring ethnic identity and its impact on economic behavior. J Eur Econ Assoc 6(2-3):424-433

Huinink J, Brüderl J, Nauck B, Walper S, Castiglioni L, Feldhaus M (2011) Panel analysis of intimate relationships and family dynamics (pairfam): conceptual framework and design. J Family Res 23(1):77-100

Jasso G, Massey DS, Rosenzweig MR, Smith JP (2000) The new immigrant survey pilot (NIS-P=: overview and new findings about U.S. legal immigrants at admission. Demography 37(1):127-138

Kong ST (2010) Rural-Urban Migration in China: Survey Design and Implementation. In: Meng X, Manning C, Shi L, Effendi T (ed) The Great Migration: Rural-Urban Migration in China and Indonesia. Edward Elgar Publ. Ltd

Konle-Seidl R, Eichhorst W, Grienberger-Zingerle M (2010) Activation policies in Germany: from status protection to basic income support. GermanPolicy 6:59-100 
Krause A (2013) Don't worry, be happy? Happiness and reemployment. J Econ Behav Organ. 96:1-20 doi: http://dx.doi. org/10.1016/j.jebo.2013.09.002

OECD (2013) OECD Employment Outlook 2013. OECD Publishing, Paris

Rinne U, Uhlendorff A, Zhao Z (2013) Vouchers and Caseworkers in Training Programs for the Unemployed. In: Empirical Economics. 45:1089-1127 doi:http://dx.doi.org/10.1007/s00181-012-0662-5

Solga H, Wagner GG (2007) A modern statistical infrastructure for excellent research and policy advice-report on the German council for social and economic data during its first period in office (2004-2006). J Appl Soc Sci Stud 127(2):315-320

10.1186/2193-9012-3-6

Cite this article as: Arni et al: The IZA evaluation dataset survey: a scientific use file. IZA Journal of European Labor Studies 2014, 3:6

Submit your manuscript to a SpringerOpen ${ }^{\odot}$ journal and benefit from:

- Convenient online submission

- Rigorous peer review

- Immediate publication on acceptance

- Open access: articles freely available online

- High visibility within the field

- Retaining the copyright to your article

Submit your next manuscript at $\boldsymbol{\nabla}$ springeropen.com 